Journal of Applied Pharmaceutical Science Vol. 6 (12), pp. 056-060, December, 2016

Available online at http://www.japsonline.com

DOI: $10.7324 / \mathrm{JAPS} .2016 .601208$

ISSN 2231-3354 (cc)) EY-NC-SA

\title{
Evaluation of the anti-diarrheal activity of methanol extract and its fractions of Urena sinuata L. (Borss) leaves
}

\author{
Mir Muhammad Nasir Uddin ${ }^{1}$, Sumyya Zahan ${ }^{1}$, Md. Ashiqul Islam ${ }^{1}$, Shahriar Ahmed ${ }^{1}$, Tajbiha-E-Mowla ${ }^{1}$, \\ Mohammad Sofiqur Rahman ${ }^{2}$, Ramiz Ahmed Sultan ${ }^{1}$, Talha Bin Emran ${ }^{3,4,5^{*}}$ \\ ${ }^{1}$ Department of Pharmacy, University of Chittagong, Chittagong-4331, Bangladesh. \\ ${ }^{2}$ Drug Management and Policy, Division of Pharmaceutical Sciences, Kakuma-machi, Kanazawa 920-1192, Japan. \\ ${ }^{3}$ Laboratory of Vaccinology and Applied Immunology, Kanazawa University School of Pharmacy, Kakuma-machi, Kanazawa 920-1192, Japan. \\ ${ }^{4}$ Department of Pharmacy, BGC Trust University Bangladesh, Chittagong-4000, Bangladesh. \\ ${ }^{5}$ Department of Biochemistry and Molecular Biology, University of Chittagong, Chittagong-4331, Bangladesh.
}

\begin{tabular}{l} 
ARTICLE INFO \\
\hline Article history: \\
Received on: $30 / 06 / 2016$ \\
Revised on: $17 / 10 / 2016$ \\
Accepted on: $14 / 11 / 2016$ \\
Available online: $28 / 12 / 2016$ \\
\hline Key words: \\
Anti-diarrheal activity; \\
Urena sinuata L.; Castor oil; \\
Enteropooling; Intestinal \\
transit; Solvent-solvent \\
partitioning.
\end{tabular}

\begin{abstract}
Objectives: Diarrhoeal disease is often a leading source of mortality and morbidity, especially among children in developing countries causing a major healthcare problem. As per suggestion of WHO, treatment of diarrhoea with traditional medicine is the main focus of our present studies. The present study is designed to evaluate the anti-diarrhoeal activity of crude methanol extract of Urena sinuata L. (U. sinuata) and its fractions.

Methods: Crude methanol extracts are obtained by in vacue methods and its fractionating is done by Kupchan partitioning method. The anti-diarrhoeal activity is screened by castor oil-induced diarrhoea, castor oil-induced enteropooling and gastrointestinal motility test.

Results: The diarrheal severity was reduced significantly $(P<0.01)$ by ethyl acetate fraction by $37.01 \%$ whereas $44.78 \%$ inhibition was found for standard drug loperamide at $5 \mathrm{mg} / \mathrm{kg}$. The two fractions namely hydro methanol, ethyl acetate and crude methanol extract also significantly $(P<0.01)$ reduced the intestinal volume in case of castor oil induced enteropooling.

Conclusion: It is concluded that, leaves of $U$. sinuata contains bioactive natural substances with anti-diarrhoeal properties. These attributes may give a justification for your use of $U$. sinuata in diarrhoea management by traditional healers.
\end{abstract}

\section{INTRODUCTION}

Diarrhoeal disease is often a leading source of mortality and morbidity, especially among children in developing countries causing a major healthcare problem (Chitme et al., 2004). Microorganisms including Shigella flexneri, Staphylococcus aureus, Escherichia coli, Salmonella typhi, Aeromonas hydrophila, Plesiomonas shigelloides are only to be major causative agents of diarrhoea in humans (Brenden et al., 1988; Janda and Abbott, 2010; Umer et al., 2013). Candida albicans has also been recognised to cause diarrhoea in humans

\footnotetext{
* Corresponding Author

Talha Bin Emran, Laboratory of Vaccinology and Applied Immunology, Kanazawa University School of Pharmacy, Kakuma-machi, Kanazawa 920-1192, Japan. Email: talhabmb@stu.kanazawa-u.ac.jp
}

(Krause et al., 2001). It was reported that, in fact, due to diarrhoea, that $50 \%$ of deaths attributed to diarrhoea combined with respiratory disease were due to diarrhoea, and that one-third of deaths due to combined measles with diarrhoea or respiratory disease were due to diarrhoea. With these assumptions, using the most recently available national verbal autopsy data (1999-2003), diarrhoea accounted for 5.4 deaths per 1,000 children in Bangladesh (Baqui et al., 2001; Luby et al., 2008). The sickness is characterised by a discharge of semi-solid or watery fecal matter on the bowels three or even more times every day (Hirschhorn, 1980; Snyder and Merson, 1982). It requires a rise in the fluidity, volume and frequency of going number two or three, abdominal pain associated with increased secretion and decreased absorption of fluid thereby loosing water and electrolytes (Fontaine; Field et al., 1989). 
However, regardless of the use of vast spectrum of approaches for diarrhoeal management, the greater parts of an individual in developing countries make use of herbal drugs to the management of diarrhoea. WHO has encouraged studies for treatment and protection against diarrhoeal diseases depending on traditional medical practices (Atta and Mouneir, 2004). Therefore, medicinal plants represent a promising source for the discovery of new anti-diarrhoeal agents (Maikere-Faniyo et al., 1989). Urena sinuata L. (Family: Malvaceae) is often a wild shrubby plant by folk medicinal use in its native areas. It is additionally known while using synonyms $U$. lobata, U. morifolia, U. moricata, $U$. paradoxaand $U$. swartzii. Various varieties of this plant grow in different tropical and subtropical areas throughout the world. The roots are sweet, slightly cooling, anti-rheumatic and antipyretic. A decoction on the stem and roots is employed in Brazil like a remedy of severe windy colic. A poultice prepared from the roots and leaves are needed as an emollient and are particularly given for snakebites, sprains and bruises. The flowers are administered as expectorant in dry and inveterate coughs. An infusion from the flowers is needed as a gargle raw throat bronchitis (Kirtikar, 1965).

In India the fundamental is utilized just as one external application for lumbago. It's for reproductive purposes in the Pacific, Trinidad and Tobago, China and India (Browner, 1985) for specific human problems of both the genders (Lans, 2007). It is just a popular diuretic in Assam, and in addition used as an abortifacient. In Philippines, the fundamental is considered as emollient, refrigerant and maturant; the leaves are prescribed in inflammation on the intestines and also the bladder. A decoction of dried root is utilized in enteritis, dysentery, rheumatic pains and tonsillitis.

Anyway, some view the rose like a medicinal plant, some deem a weed, but others utilize its fiber (Aramina fiber) for assorted purposes in Madagascar, Nigeria and Western Sudan, Chad, Central African Republic, Zaire and Gabon, which is told proof against damage by termites and water (Anon, 1976; Ahmed, 2009). However, house elevators its biological activity on diarrhoea remains to be scanty. For this reason the flower was considered for your investigation of its anti-diarrhoeal activity.

\section{MATERIALS AND METHODS}

\section{Drugs and chemicals}

Methanol was bought from SIGMA® (Sigma-Aldrich®, St Louis, USA), while loperamide manufactured by Square Pharmaceuticals Ltd., Bangladesh, was bought from local pharmacy. Castor oil was purchased from WELL's Heath Care, Spain. All the chemicals and reagents were analytical grade.

\section{Ethical statement}

All experimental protocols were in compliance with Dhaka University Ethics Committee (approval number AE-DUEC 2012/118) on research in animals as well as internationally accepted principles for laboratory animal use and care (Zimmermann).

\section{Plant material}

The plant was collected from University of Chittagong campus in 2011. The plant was taxonomically identified by Dr. Shaikh Bokhtear Uddin, Professor, Department of Botany, University of Chittagong. The sample specimens of the identified plants have been preserved in the national herbarium with the mentioned accession numbers. The plant leaves were thoroughly washed with water and were dried in a hot air oven at room temperature $(25 \pm 1){ }^{\circ} \mathrm{C}$ for 7 days in two days interval and at $40^{\circ} \mathrm{C}$ for the next 2 days.

\section{Extraction of the plant material and sample preparation}

Weighed (600 $\mathrm{g}$ of the dried and powdered) sample was soaked in $1500 \mathrm{~mL}$ of $99 \%$ Methanol (Merck KGaA, Germany) in clean, sterilized and flat-bottomed glass container. Afterwards, it was sealed and maintained for 15 days accompanying occasional stirring and agitation. The complete mixture was then subjected to coarse filtration on a piece of clean, white sterilized cotton material and Whatman ${ }^{\circledR}$ filter paper. The extract was obtained by evaporation using rotary evaporator (Bibby RE-200, Sterilin Ltd., $\mathrm{UK})$ at $4 \mathrm{rpm}$ and $65^{\circ} \mathrm{C}$ temperature. It rendered a gummy concentrate of greenish black color. The gummy concentrate was designated as crude extract, or Methanol extract. Then the crude methanolic extract was dried by freeze drier and preserved at $+4^{\circ} \mathrm{C}$ (yield 13.56\% w/w).

After that, solvent-solvent partitioning was done by using the protocol designed by Kupchan and Tsou (1973) (Kupchan et al., 1973) and modified version of Wagenen et al., (1993). The crude extract was $(5 \mathrm{~g})$ was triturated by dissolved in $10 \%$ aqueous methanol (methanol: water; $9: 1 \mathrm{v} / \mathrm{v}$ ) to make the mother solution which was partitioned off successively by four solvents such as nhexane, chloroform, ethyl acetate and hydro-methanolin order of increasing polarity by using separating funnel (Figure 1). The amount of extract found after partitioning and their physical appearances are shown in Table 1. All the four fractions of each plant extract were dried by evaporating respective solvent using rotary evaporator. All extracts were stored at $4^{\circ} \mathrm{C}$ in airtight containers till further analysis (Bibi et al., 2011).

\section{Experimental Animal}

Albino Wistar rats (Rattus norvigicus) of either sex weighing 120-150 g were also used for the present study. They were purchased from the animal house of Jahangirnagar University, Savar, Dhaka-1342, Bangladesh. They were maintained in the animal house of North South University, Bashundhara, Dhaka-1229, Bangladesh for experimental purpose. The animals were maintained under controlled conditions of temperature $\left(23 \pm 2^{\circ} \mathrm{C}\right)$, humidity $(50 \pm 5 \%)$ and $12 \mathrm{~h}$ light-dark cycles. All the animals were acclimatized for seven days before the study. The animals were randomized into experimental and control groups and housed individually in sanitized polypropylene cages 
containing sterile paddy husk as bedding. They had free access to standard pellets as basal diet and water ad libitum. Animals were habituated to laboratory conditions for $48 \mathrm{~h}$ prior to experimental protocol to minimize if any of non-specific stress.

\section{Antidiarrheal activity \\ Castor oil induced diarrhoea}

Castor oil-induced diarrhoea was done according to the method of Soba et al. (Shoba and Thomas, 2001) and Uddin et al (Uddin et al., 2005). Rats of either sex were divided into twelve groups of four rats each. The animals were fasted for $18 \mathrm{~h}$ prior to the test. Group I was treated with normal saline $(2 \mathrm{~mL} / \mathrm{kg})$, which served as control; while Group II received loperamide $(5 \mathrm{mg} / \mathrm{kg})$. Groups III, IV, V, VI, and VII received orally 200 or $400 \mathrm{mg} / \mathrm{kg}$ of methanol, n-hexane, chloroform, ethyl acetate and hydro-methanol respectively received methanol and petroleum ether extracts (200 $\mathrm{mg} / \mathrm{kg}$ ). All doses were administered orally. After $1 \mathrm{~h}$, all groups received $1 \mathrm{~mL}$ of castor oil orally.

Then animals were placed in cages lined with adsorbent papers and observed for $4 \mathrm{~h}$ for the presence of diarrhoea defined as watery (wet), unformed stool. The control group result was considered as $100 \%$. The activity of each group was expressed as percent inhibition (\%) of diarrhoea. The percent inhibition of defecation was calculated as follows:

$\%$ Inhibition of defecation $=[(\mathrm{A}-\mathrm{B}) / \mathrm{A}] \times 100$

Where A indicated mean number of defecation caused by castor oil; B indicated mean number of defecation caused by drug or extract.

\section{Castor oil induced enteropooling}

The castor oil-induced enteropooling was carried out according to the method of Robert et al. Rats of either sex were divided into twelve groups of four rats each. The animals were fasted for $18 \mathrm{~h}$ prior to the test. Group I was treated with normal saline $(2 \mathrm{~mL} / \mathrm{kg})$, which served as control; while Group II received loperamide $(5 \mathrm{mg} / \mathrm{kg})$.

Groups III, IV, V, VI, and VII received orally 200 or $400 \mathrm{mg} / \mathrm{kg}$ of methanol, n-hexane, chloroform, ethyl acetate and hydro-methanol respectively received methanol and petroleum ether extracts $(200 \mathrm{mg} / \mathrm{kg})$. One hour later, all the rats were challenged with $1 \mathrm{~mL}$ of castor oil orally. After $1 \mathrm{~h}$ of castor oil received, the rats were sacrificed and the small intestine from the pylorus to the caecum was isolated. Then the intestinal contents were weighed and volume measured by graduated tube (Robert et al., 1976).

\section{Gastrointestinal motility test}

This test was performed according to the method previously described using charcoal as a diet marker (Meite, 2009). Rats of either sex were divided into twelve groups of four rats each. The animals were fasted for $18 \mathrm{~h}$ prior to the test. Group I was treated with normal saline $(2 \mathrm{~mL} / \mathrm{kg})$, which served as control; while Group II received loperamide ( $5 \mathrm{mg} / \mathrm{kg}$ ). Groups III, IV, V, VI, and VII received orally 200 or $400 \mathrm{mg} / \mathrm{kg}$ of methanol, n-hexane, chloroform, ethyl acetate and hydro-methanol respectively received methanol and petroleum ether extracts (200 $\mathrm{mg} / \mathrm{kg}$ ). After $1 \mathrm{~h}$ of drug administration, all animals were received $1 \mathrm{~mL}$ of charcoal meal $(10 \%$ charcoal suspension in $5 \%$ gum acacia) orally.

One hour later, all animals were sacrificed, and the distance covered by the charcoal meal in the intestine from the pylorus to the caecum was measured and expressed as percentage of distance moved (Marona and Lucchesi, 2004).

\section{Statistical analysis}

All analyses were carried out in triplicates. Data were presented as mean \pm SEM. The significance of difference between the control and treated groups was determined using twoway analysis of variance (ANOVA), followed by Student's $t$-test. $P$ value of 0.05 or 0.01 was considered as significant.

\section{RESULTS}

\section{Castor oil induced diarrhoea}

In castor oil induced diarrhoea test, ethyl acetate showed considerable anti-diarrheal effect in rats. Methanol extract significantly inhibited the frequency of defecation $(41.75 \%)$ when compared with untreated control rats $(P<0.01)$. The fraction decreased the entire number of wet feces produced upon administration of castor oil when compared to the castor oil treated rats.

The crude methanol extract, chloroform fraction and hydro methanol fraction are also showed significant effect $(P<$ 0.05 ) with an inhibition of defection $38.28 \%, 27.18 \%, 37.73 \%$ respectively. The results are shown in Table 1.

\section{Castor oil induced enteropooling}

All of the extracts showed noticeable effect in castor oil induced entropooling test in the rats. The intestinal volume was decreased by $56.64 \%$ for hydro methanol extract and $60.69 \%$ for loperamide $(5 \mathrm{mg} / \mathrm{kg})$.

The values were statistically more significant $(P<0.01)$. Other fractions and crude, chloroform, ethyl acetate, n-hexane and methanol are also significantly inhibited intestinal fluid accumulation $(P<0.05)$ and the effect of the extract was less potent in comparison to the standard drug. All the data are shown in Table 2.

\section{Gastrointestinal motility test}

The gastrointestinal distance travelled by the charcoal meal in the rats significantly $(P<0.01)$ lessened by methanol, hydro methanol and ethyl acetate fractions compared with the control group (Table 3 ). Loperamide $(5 \mathrm{mg} / \mathrm{kg}$ ) produced a marked decrease $(42.30 \%)$ in the propulsion of charcoal meal through gastrointestinal tract. 
Table 1: Effect of different fractions and crude extract of leaves of $U$. sinuata on castor oil induced diarrhoea in rats

\begin{tabular}{|c|c|c|c|c|c|}
\hline Groups & Treatment (p.o.) & Total number of feces & $\begin{array}{l}\text { \% Inhibition of } \\
\text { defecation }\end{array}$ & $\begin{array}{c}\text { Total number of diarrheal } \\
\text { feces }\end{array}$ & $\begin{array}{l}\text { \% Inhibition of } \\
\text { diarrhea }\end{array}$ \\
\hline I & Saline $(2 \mathrm{~mL} / \mathrm{kg})$ & $18.87 \pm 1.33$ & - & $10.05 \pm 1.88$ & - \\
\hline II & Loperamide $(5 \mathrm{mg} / \mathrm{kg})$ & $8.76 \pm 0.56^{* *}$ & 51.82 & $5.55 \pm 0.43 * *$ & 44.78 \\
\hline III & MEUS (200 mg/kg) & $11.22 \pm 0.99^{*}$ & 38.28 & $7.32 \pm 0.87^{*}$ & 27.16 \\
\hline IV & CEUS (200 mg/kg) & $13.25 \pm 0.80 *$ & 27.18 & $7.80 \pm 0.41 *$ & 22.39 \\
\hline V & HXUS (200 mg/kg) & $14.41 \pm 1.31$ & 20.74 & $7.99 \pm 0.53$ & 20.50 \\
\hline VI & ETUS $(200 \mathrm{mg} / \mathrm{kg})$ & $10.59 \pm 0.49 * *$ & 41.75 & $6.33 \pm 0.85 * *$ & 37.01 \\
\hline VI & HMUS (200 mg/kg) & $11.32 \pm 0.79 *$ & 37.73 & $6.88 \pm 0.85^{*}$ & 31.54 \\
\hline
\end{tabular}

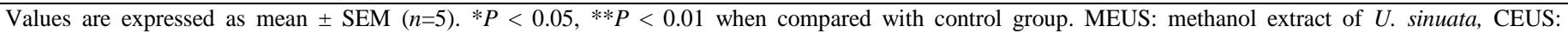
Chloroform fraction of $U$. sinuata, HXUS: n-hexane fraction of $U$. sinuata,

ETUS: Ethyl acetate fraction U. sinuata and HMUS: Hydromethanol fraction of $U$. sinuata.

Table 2: Effect of different fractions and crude extract of leaves of $U$. sinuata on castor oil induced enteropooling in rats.

\begin{tabular}{|c|c|c|c|c|}
\hline Groups & Treatment (p.o.) & Total length of intestinal content (g) & Volume of intestinal content (mL) & Inhibition (\%) \\
\hline I & Saline $(2 \mathrm{~mL} / \mathrm{kg})$ & $4.28 \pm 0.77$ & $3.99 \pm 0.38$ & - \\
\hline II & Loperamide ( $5 \mathrm{mg} / \mathrm{kg}$ ) & $1.53 \pm 0.05 * *$ & $1.28 \pm 0.18^{* *}$ & 60.89 \\
\hline III & MEUS (200 mg/kg) & $2.78 \pm 0.99 *$ & $1.89 \pm 0.86^{*}$ & 52.63 \\
\hline IV & CEUS (200 mg/kg) & $2.58 \pm 0.25 *$ & $2.89 \pm 0.30 *$ & 27.56 \\
\hline $\mathrm{V}$ & HXUS (200 mg/kg) & $3.01 \pm 1.01 *$ & $2.77 \pm 0.65^{*}$ & 30.58 \\
\hline VI & ETUS $(200 \mathrm{mg} / \mathrm{kg})$ & $2.48 \pm 0.89 *$ & $1.93 \pm 0.53 *$ & 51.62 \\
\hline VI & HMUS (200 mg/kg) & $2.39 \pm 0.63 * *$ & $1.73 \pm 0.87 * *$ & 56.64 \\
\hline
\end{tabular}

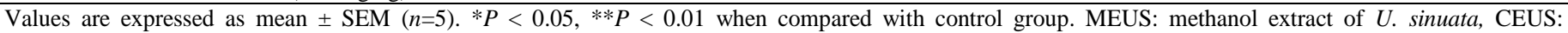

Chloroform fraction of $U$. sinuata, HXUS: n-hexane fraction of $U$. sinuata,

ETUS: Ethyl acetate fraction U. sinuata and HMUS: Hydromethanol fraction of $U$. sinuata.

Table 3: Effect of different fractions and crude extract of leaves of $U$. sinuata on small intestinal transit in rats.

\begin{tabular}{|c|c|c|c|c|}
\hline Groups & Treatment (p.o.) & Total length of intestine $(\mathrm{cm})$ & Distance traveled by marker $(\mathrm{cm})$ & Inhibition (\%) \\
\hline I & Saline $(2 \mathrm{~mL} / \mathrm{kg})$ & $109.87 \pm 2.13$ & $101.69 \pm 2.25$ & 7.45 \\
\hline II & Loperamide $(5 \mathrm{mg} / \mathrm{kg})$ & $102.88 \pm 1.23$ & $59.36 \pm 3.15 * *$ & 42.30 \\
\hline III & MEUS $(200 \mathrm{mg} / \mathrm{kg})$ & $92.32 \pm 1.85$ & $65.13 \pm 0.77 * *$ & 29.45 \\
\hline IV & CEUS (200 mg/kg) & $91.50 \pm 1.80$ & $73.63 \pm 0.52 *$ & 19.53 \\
\hline V & HXUS (200 mg/kg) & $95.43 \pm 1.77$ & $77.63 \pm 1.88^{*}$ & 18.65 \\
\hline VI & ETUS $(200 \mathrm{mg} / \mathrm{kg})$ & $94.44 \pm 2.02$ & $64.52 \pm 0.76 * *$ & 31.68 \\
\hline VI & HMUS (200 mg/kg) & $99.58 \pm 1.02$ & $67.25 \pm 1.13 * *$ & 32.47 \\
\hline
\end{tabular}

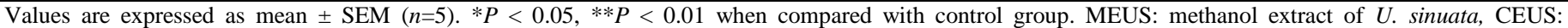

Chloroform fraction of $U$. sinuata, HXUS: n-hexane fraction of $U$. sinuata, ETUS:

Ethyl acetate fraction $U$. sinuata and HMUS: Hydromethanol fraction of $U$. sinuata.

\section{DISCUSSION}

Diarrhoea is frequently considered a consequence of altered motility and fluid accumulation within the intestinal tract. The act of using castor oil as being a diarrheal inductor has become largely studied, and it is active component is ricinoleic acid, which produces an irritating and inflammatory action on the intestinal mucosa, leading to the discharge of prostaglandins. This disorder enhances the permeability in the mucosal cells and provokes alterations in electrolyte transport thus causing diarrhea (Watson and Gordon, 1962; Mascolo et al., 1993; Kase et al., 1999; Tunaru et al., 2012). Prostaglandins on the E series are viewed as for being good diarrheogenic agents in experimental animals and world. The inhibitors of prostaglandins biosynthesis are therefore considered to delay using castor oil-induced diarrhoea (Tunaru et al., 2012). The present study sought to assess the antidiarrheal activity of $U$. sinuata. Our study showed that methanol extract of $U$. sinuata and its different fraction significantly inhibited castor oil-induced diarrhoea in rats, as shown by the significant reduction of the number of diarrhoeal and total faeces. Plant extracts containing tannin, flavonoids, alkaloids, saponins and steroids have been reported to possess antidiarrheal activity (Umer et al., 2013). The leaves of $U$. sinuata comprise numerous alkaloids which may be responsible for its consequence. The assumed effects were noticeable considering with the standard drug, loperamide at $5 \mathrm{mg} / \mathrm{kg}$. In our study, we have shown the experimental data for one dose $(200 \mathrm{mg} / \mathrm{kg})$ only, for both extract and fractions. Loperamide, apart from governing the alimentary tract, is usually reported to reduce transit from the intestine, reduce colon flow rates and consequently produce any profit on colonic motility (Camilleri, 2004). Both extract and fractions moderately reduced intestinal transit from the decline in the length traveled by charcoal meal. The antimuscarinic drug and atropine decreased the propulsive movement in the charcoal meal study because anticholinergic effect (Rahman et al., 2013). From the result, we established that the extracts suppressed the propulsion of charcoal meal by increasing the absorption of water and electrolytes. 


\section{CONCLUSION}

Our results exhibit that the leaves extract of $U$. sinuata and its fractions contains bioactive natural substances with antidiarrheal properties. These attributes may give a justification for the use of $U$. sinuata in diarrhoea management by traditional healers. But further studies are also required to identify the phytoconstituents responsible for these bioactivities and to establish the mechanism of action of antidiarrheal activity.

\section{Abbreviations}

$\mathrm{WHO}=$ World Health Organization; $\mathrm{h}=$ Hour; $\mathrm{min}=$ Minutes; sec $=$ Second; kg= Kilogram; $g=$ Gram; $\mu \mathrm{g}=$ Microgram; $\mathrm{L}=$ Liter; $\mathrm{mL}=$ Millilitre; $\mathrm{mg} / \mathrm{kg}=$ Milligram per kilogram; $\%=$ Percent; b.w. $=$ Body Weight $;{ }^{\circ} \mathrm{C}=$ Degree Celsius; et al. $=$ et alliori (and others); SEM= Standard Error Mean; MEUS $=$ methanol extract of $U$. sinuata; CEUS= Chloroform fraction of $U$. sinuata; HXUS = n-hexane fraction of $U$. sinuata ETUS $=$ Ethyl acetate fraction $U$. sinuata; HMUS= Hydromethanol fraction of $U$. sinuata; i. p.= intra-peritoneal.

\section{Financial support and sponsorship: Nil.}

Conflict of Interests: There are no conflicts of interest.

\section{REFERENCES}

Ahmed Z.U. Hmabzntkm, Kabir SMH, Ahmad M and Ahmed ATA. Encyclopedia of Flora and Fauna of Bangladesh. Asiatic Society of Bangladesh 2009; 9: 59-60.

Atta AH, Mouneir SM. Antidiarrhoeal activity of some Egyptian medicinal plant extracts. J Ethnopharmacol 2004; 92:303-9.

Baqui AH, Sabir AA, Begum N, et al. Causes of childhood deaths in Bangladesh: an update. Acta Paediatr 2000; 190: 682-90.

Bibi Y, Nisa S, Chaudhary FM, et al. Antibacterial activity of some selected medicinal plants of Pakistan. BMC Complement Altern Med 2011; 11: 1472-6882.

Brenden RA, Miller MA, Janda JM. Clinical disease spectrum and pathogenic factors associated with Plesiomonas shigelloides infections in humans. Rev Infect Di 1988; 10: 303-16.

Browner CH. Plants used for reproductive health in Oaxaca, Mexico. Econ Bot 1985; 39: 482-504.

Camilleri M. Chronic diarrhea: a review on pathophysiology and management for the clinical gastroenterologist. Clin Gastroenterol Hepatol 2004; 2: 198-206.

Chitme HR, Chandra M, Kaushik S. Studies on anti-diarrhoeal activity of Calotropis gigantea R.Br. in experimental animals. J Pharm Pharm Sci 2004; 7: 70-5.

Field M, Rao MC, Chang EB. Intestinal electrolyte transport and diarrheal disease (1). N Engl J Med 1989; 321: 800-6.

Fontaine O Bacterial diarrhoea and treatment, Lancet 1988; 28: $1234-5$

Hirschhorn N. The treatment of acute diarrhea in children. An historical and physiological perspective. Am J Clin Nutr 1980; 33: 63763.

Janda JM, Abbott SL. The genus Aeromonas: taxonomy, pathogenicity, and infection. Clin Microbiol Rev 2010; 23: 35-73.

Kase Y, Saitoh K, Makino B, et al. Relationship between the antidiarrhoeal effects of Hange-Shashin-To and its active components. Phytother Res 1999; 13: 468-73.
Kirtikar KR. Indian Medicinal Plants (2nd Ed.) Basu L.M., Allahabad, India 1965; 3: 1606-9.

Krause R, Schwab E, Bachhiesl D, et al. Role of Candida in Antibiotic-Associated Diarrhea. Journal of Infectious Diseases 2001; 184: 1065-9.

Kupchan SM, Tsou G, Sigel CW. Datiscacin, a novel cytotoxic cucurbitacin 20-acetate from Datisca glomerata. J Org Chem 1973; 38: 1420-1.

Lans C. Ethnomedicines used in Trinidad and Tobago for reproductive problems. J Ethnobiol Ethnomed 2007; 3: 13

Luby SP, Brooks WA, Zaman K, et al. Infectious diseases and vaccine sciences: strategic directions. J Health Popul Nutr 2008; 26: $295-$ 310.

Maikere-Faniyo R, Van Puyvelde L, Mutwewingabo A, et al. Study of Rwandese medicinal plants used in the treatment of diarrhoea I. $J$ Ethnopharmacol 1989; 26: 101-9.

Marona HR, Lucchesi MB. Protocol to refine intestinal motility test in mice. Lab Anim 2004; 38: 257-60.

Mascolo N, Izzo AA, Barbato F, et al. Inhibitors of nitric oxide synthetase prevent castor-oil-induced diarrhoea in the rat. Br J Pharmacol 1993; 108: 861-4.

Meite S NJ, Bahi C, Yapi HF, Djaman AJ, Guede GF. Antidiarrhoeal activity of the ethyl acetate extract of Morinda morindoides in rats. Tropical Journal of Pharmaceutical Research 2009; 8: 201-7.

Rahman MK, Barua S, Islam MF, et al. Studies on the antidiarrheal properties of leaf extract of Desmodium puchellum. Asian Pac J Trop Biomed 2013; 3: 639-43.

Robert A, Nezamis JE, Lancaster C, et al. Enteropooling assay: a test for diarrhea produced by prostaglandins. Prostaglandins 1976; 11: 809-28.

Shoba FG, Thomas M. Study of antidiarrhoeal activity of four medicinal plants in castor-oil induced diarrhoea. J Ethnopharmacol 2001; 76: $73-6$.

Snyder JD, Merson MH . The magnitude of the global problem of acute diarrhoeal disease: a review of active surveillance data. Bull World Health Organ 1982; 60: 605-13.

Tunaru S, Althoff TF, Nusing RM, et al. Castor oil induces laxation and uterus contraction via ricinoleic acid activating prostaglandin EP3 receptors. Proc Natl Acad Sci U S A 2012; 109: 9179-84.

Uddin SJ, Shilpi JA, Alam SM, et al. Antidiarrhoeal activity of the methanol extract of the barks of Xylocarpus moluccensis in castor oiland magnesium sulphate-induced diarrhoea models in mice. $J$ Ethnopharmacol 2005; 101: 139-43.

Umer S, Tekewe A, Kebede N. Antidiarrhoeal and antimicrobial activity of Calpurnia aurea leaf extract. BMC Complement Altern Med 2013; 13: 1472-6882.

Watson WC, Gordon RS, Jr. Studies on the digestion, absorption and metabolism of castor oil. Biochem Pharmacol 1962; 11, 229-36.

Zimmermann M. Ethical guidelines for investigations of experimental pain in conscious animals, Pain. 1983; 16: 109-10.

\section{How to cite this article:}

NasirUddin MM, Zahan S, Islam A, Ahmed S, Mowla TE, Rahman MS, Emran TB. Evaluation of the anti-diarrheal activity of methanol extract and its fractions of Urena sinuata L. (Borss) leaves. J App Pharm Sci, 2016; 6 (12): 056-060. 